\title{
Basin-scale climate control on terrestrial biospheric carbon turnover
}

\author{
V. GALY ${ }^{1}$, T. EGLINTON ${ }^{1,2}$, J. HEMINGWAY $^{1,3}$, X. FenG $^{4}$
}

${ }^{1}$ Department of Marine Chemistry \& Geochemistry, Woods Hole Oceanographic Institution, U.S.A. (vgaly@whoi.edu)

${ }^{2}$ Department of Earth Sciences, ETH Zurich, Switzerland

${ }^{3}$ Department of Earth and Planetary Sciences, Harvard University, U.S.A.

${ }^{4}$ State Key Laboratory of Vegetation and Environmental Change, Institute of Botany, Chinese Academy of Sciences, China

Terrestrial vegetation and soils hold about three times more carbon than the atmosphere. Much debate concerns how anthropogenic activity will perturb these large surface carbon reservoirs, potentially exacerbating on-going changes to the climate system. In particular, uncertainties persist in extrapolating point-source observations to ecosystem-scale budgets and fluxes, which require consideration of vertical and lateral processes on multiple temporal and spatial scales. To explore controls on organic carbon turnover at the river basin scale, we compile new and pre-existing radiocarbon $\left({ }^{14} \mathrm{C}\right)$ data on two groups of molecular tracers of plant-derived carbon - leaf-wax lipids and lignin phenols - from a globally distributed suite of rivers collectively accounting for $42 / 29 / 20 \%$ of the global riverine water/sediment/particulate organic carbon discharge, respectively. Our dataset reveals significant negative relationships between the ${ }^{14} \mathrm{C}$ age of these molecular biomarkers and mean annual temperature and precipitation spatially averged over the river catchments. Moreover, riverine biospheric carbon ages linearly scale with basin-wide soil carbon turnover times, implicating organic carbon cycling within soils as a primary control. The systematic offset observed between riverine biospheric carbon age and soil carbon turnover time is ascribed to lateral export of refractory, mineral-associated carbon and/or to a broad distribution of organic matter reactivities. Differences between plant-wax and lignin-phenol ${ }^{14} \mathrm{C}$ ages reflect their modes of mineral association, reactivities and transport vectors. Scaling of riverine biospheric carbon ages with soil carbon turnover suggests the former can constrain the sensitivity of carbon dynamics to environmental controls on river basin scales. Extracting this information from fluviallydominated sedimentary sequences may thus inform past variations in soil turnover in response to anthropogenic and/or climate perturbations. 